\title{
A method for detecting the presence of organic fraction in nucleation mode sized particles
}

\author{
P. Vaattovaara ${ }^{1}$, M. Räsänen ${ }^{1}$, T. Kühn ${ }^{2}$, J. Joutsensaari ${ }^{3}$, and A. Laaksonen ${ }^{1}$ \\ ${ }^{1}$ Department of Applied Physics, University of Kuopio, P.O. Box 1627, 70211 Kuopio, Finland \\ ${ }^{2}$ Institute for Analytical Sciences, P.O. Box 101 352, 44013 Dortmund, Germany \\ ${ }^{3}$ Department of Environmental Sciences, University of Kuopio, P.O. Box 1627, 70211 Kuopio, Finland
}

Received: 16 March 2005 - Published in Atmos. Chem. Phys. Discuss.: 1 June 2005

Revised: 21 September 2005 - Accepted: 18 November 2005 - Published: 14 December 2005

\begin{abstract}
New particle formation and growth has a very important role in many climate processes. However, the overall knowlegde of the chemical composition of atmospheric nucleation mode (particle diameter, $\mathrm{d}<20 \mathrm{~nm}$ ) and the lower end of Aitken mode particles $(\mathrm{d} \leq 50 \mathrm{~nm})$ is still insufficient. In this work, we have applied the UFO-TDMA (ultrafine organic tandem differential mobility analyzer) method to shed light on the presence of an organic fraction in the nucleation mode size class in different atmospheric environments. The basic principle of the organic fraction detection is based on our laboratory UFO-TDMA measurements with organic and inorganic compounds. Our laboratory measurements indicate that the usefulness of the UFO-TDMA in the field experiments would arise especially from the fact that atmospherically the most relevant inorganic compounds do not grow in subsaturated ethanol vapor, when particle size is $10 \mathrm{~nm}$ in diameter and saturation ratio is about $86 \%$ or below it. Furthermore, internally mixed particles composed of ammonium bisulfate and sulfuric acid with sulfuric acid mass fraction $\leq 33 \%$ show no growth at $85 \%$ saturation ratio. In contrast, $10 \mathrm{~nm}$ particles composed of various oxidized organic compounds of atmospheric relevance are able to grow in those conditions. These discoveries indicate that it is possible to detect the presence of organics in atmospheric nucleation mode sized particles using the UFO-TDMA method. In the future, the UFO-TDMA is expected to be an important aid to describe the composition of atmospheric newly-formed particles.
\end{abstract}

\section{Introduction}

Newly-formed nanometer-sized particles can grow to larger aerosol particles and cloud condensation nuclei (CCN),

Correspondence to: P. Vaattovaara

(petri.vaattovaara@uku.fi) which scatter incoming radiation and contribute a direct and an indirect (via clouds) cooling effect to the Earth's radiation budget (Slingo, 1990). While a significant amount of new nanometer-sized particles are lost through coagulation scavenging, a noticeable fraction may grow by both gas-toparticle conversion and coagulation processes (Mäkelä et al., 1997) into Aitken and accumulation modes. Thus, new particle formation and growth has a very important role in many climate processes. Furthermore, ultrafine particles (particle diameter, $\mathrm{d} \leq 100 \mathrm{~nm}$ ) have been shown to relate to adverse health effects (e.g. Ibald-Mulli et al., 2002).

However, details of the processes controlling nucleation and growth in the ultrafine size range in different environments (e.g. boreal, urban, coastal) are still widely undetermined. To understand properly particle formation and growth and their effects on climate processes, the chemical composition of ultrafine particles needs to be characterized. Because of the difficulties in studying the composition of the ultrafine particles, the overall knowlegde of the chemical composition of atmospheric nucleation and the lower end of Aitken mode particles $(\mathrm{d} \leq 50 \mathrm{~nm})$ is still insufficient. Especially, below $20 \mathrm{~nm}$ (in diameter) very little information is available on particle compositions in different environments. Techniques that have been used for obtaining information on composition of particles smaller than $20 \mathrm{~nm}$ include UFH-TDMA (ultrafine hygroscopicity tandem differential mobility analyzer), Hämeri et al. (2000); TEM (transition electron microscopy), Mäkelä et al. (2002); PHA-UCPC (pulse height analyzer ultrafine condensation particle counter), O'Dowd et al. (2003) and TDCIMS (thermal desorption chemical ionization mass spectrometer), Smith et al. (2004). Overall, however, it is very difficult to perform chemical analysis of such small particles by any method, because of their very small masses, the fact that the possible constituents include hundreds or thousands of compounds, and the possibility that chemical reactions may change their composition as a function of time.

(C) 2005 Author(s). This work is licensed under a Creative Commons License. 


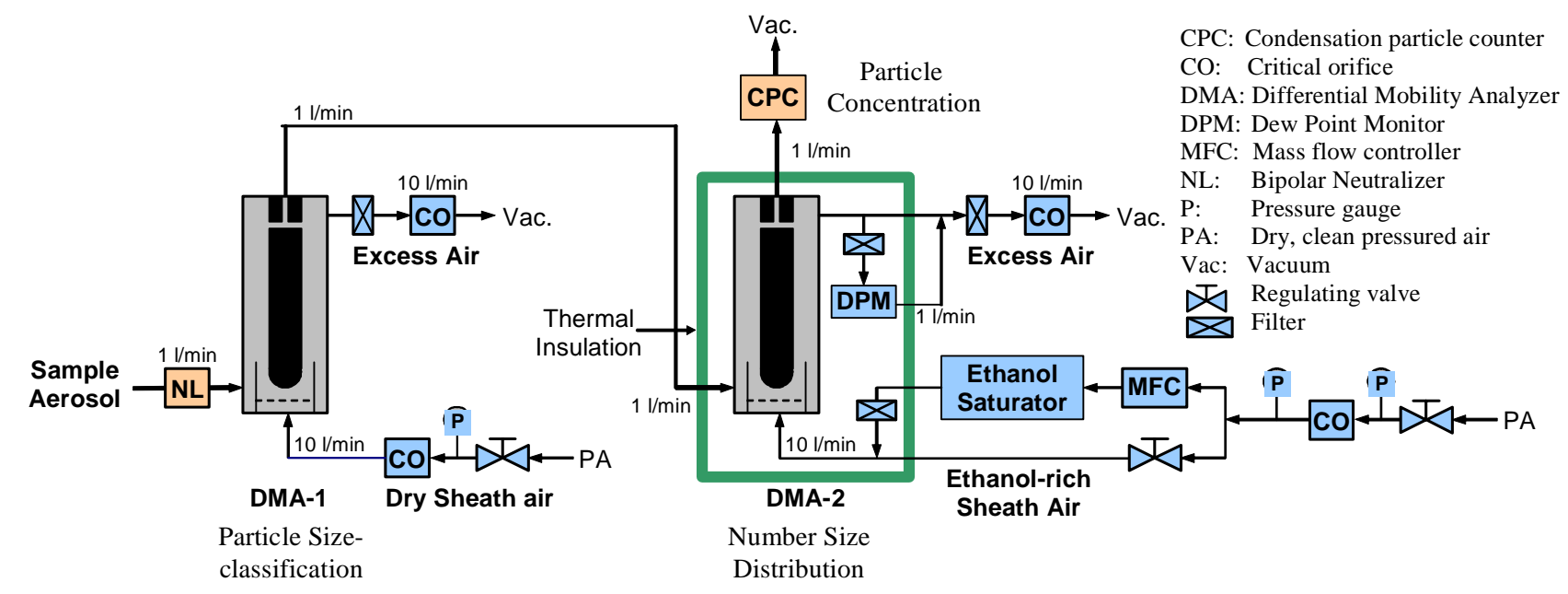

Fig. 1. A schematic picture of the UFO-TDMA system.

The ultrafine particles can be composed of inorganic and/or organic compounds, which both are known to be important in the Earth's atmospheric processes, and their presence in the nucleation mode particles is expected to be related to local environments (e.g. coastal vs. boreal). In this work, the UFO-TDMA (ultrafine organic tandem differential mobility analyzer) method has been applied to shed light on the presence of organic fraction in the nucleation mode size class (i.e. $\mathrm{d}<20 \mathrm{~nm}$ ). The basic principle of the organic fraction detection is based on our laboratory UFO-TDMA measurements with organic and inorganic compounds (measurement range $6-50 \mathrm{~nm}$ in diameter). Our laboratory measurements, presented in more details in the following sections, indicate that the usefulness of the UFO-TDMA in the field experiments would arise especially from the fact that atmospherically the most relevant inorganic compounds do not grow in subsaturated ethanol vapor, when particle size is $10 \mathrm{~nm}$ in diameter and saturation ratio is about $86 \%$ or below it. Furthermore, the internal mixtures of ammonium bisulfate and sulfuric acid with sulfuric acid mass fraction below 33\% show no growth at $85 \%$ saturation ratio when the particle size is $10 \mathrm{~nm}$. In contrast, various oxidized organic compounds of atmospheric relevance are able to grow under those conditions.

\section{Methods}

\subsection{The UFO-TDMA system}

In this work, the ultrafine organic tandem differential mobility analyzer (UFO-TDMA) was used in laboratory conditions to test growth factors (GFs) of atmospherically the most relevant inorganic and some relevant organic compounds in size classes of the lower end of ultrafine particles (i.e. $6 \leq \mathrm{d} \leq 50 \mathrm{~nm}$ ). In the present UFO-TDMA system, ethanol (purity 99.7 weight percent) is used as the organic solvent. Even though other kind of solvent types (e.g. some long chain aliphatic or nonpolar solvent) could also be useful, the first chosen solvent was ethanol. The main reasons for the selection are the following: Solubility information for different organic and inorganic compounds is well available; available information tells that various oxidized organic compounds are soluble or very soluble in ethanol whereas typical atmospheric inorganic species are not soluble or are only slightly soluble; ethanol solubility properties differ sufficiently from those of water; ethanol is not harmful, toxic, corrosive, explosive or too reactive; pure ethanol is easy to supply and storage, and the price is usually low.

Figure 1 shows a schematic diagram of the UFO-TDMA setup. The first DMA (Differential Mobility Analyzer; Hauke type, length $11 \mathrm{~cm}$; Winklmayr et al., 1991) classifies a desired size (for example, $10 \mathrm{~nm}$ ) from a polydisperse aerosol flow, after which the selected particles are introduced into air with a known solvent saturation ratio $\mathrm{S}$. The second DMA, identical to the first one, then measures the change in particle size due to the interaction with the subsaturated ethanol vapor. The growth factors, i.e., the final diameter after vapor uptake divided by the initial "dry" diameter of the particles, are characteristic for each particle composition. In the growth factor calculations, the geometric number mean diameter of the measured size distribution was used as an average particle size. The number size distributions were determined using a standard DMA data inversion algorithm (Knutson and Whitby, 1975; Reischl, 1991).

The UFO-TDMA used in this study was built following guidelines of the O-TDMA (Joutsensaari et al., 2001) system but with the some differences: Shorter DMAs (Hauke type, length $11 \mathrm{~cm}$; Winklmayr et al., 1991) and high voltage power supplies (F.u.G. Elektronik GmbH, Germany) with lower maximum voltages $(1.25 \mathrm{kV}$ for the first DMA and 
Table 1. Manufacturer, mole mass $(\mathrm{g} / \mathrm{mol})$, density $\left(\mathrm{g} / \mathrm{cm}^{3}\right)$, purity $(\%)$ and nebulized solution concentration (mol/L) information for compounds studied in this work by the UFO-TDMA. The supercripts ${ }^{1}$ and ${ }^{2}$ mean CRC Handbook of Chemistry and Physics (1996) and this work, respectively.

\begin{tabular}{|c|c|c|c|c|c|}
\hline Compounds & Manufacturer & $\mathrm{M}(\mathrm{g} / \mathrm{mol})$ & Density $\left(\mathrm{g} / \mathrm{cm}^{3}\right)$ & Purity (\%) & Conc. $(\mathrm{mol} / \mathrm{L})$ \\
\hline $\begin{array}{l}\mathrm{I}_{2} \mathrm{O}_{4} \\
\text { iodine tetroxide }\end{array}$ & selfmade $^{2}$ & 317.80 & $4.20^{1}$ & $\begin{array}{l}\text { Raman } \\
\text { checked }\end{array}$ & $\begin{array}{c}0.05 \\
0.002\end{array}$ \\
\hline $\begin{array}{l}\mathrm{I}_{2} \mathrm{O}_{5} \\
\text { iodine pentoxide }\end{array}$ & Merck & 333.80 & 4.98 & $>99$ & 0.01 \\
\hline $\begin{array}{l}\left(\mathrm{NH}_{4}\right)_{2} \mathrm{SO}_{4} \\
\text { ammonium sulfate }\end{array}$ & FF-Chemicals & 132.14 & 1.77 & $>99$ & 0.01 \\
\hline $\begin{array}{l}\left(\mathrm{NH}_{4}\right) \mathrm{HSO}_{4} \\
\text { ammonium bisulfate }\end{array}$ & Fluka & 115.11 & 1.78 & $>99$ & 0.01 \\
\hline $\begin{array}{l}\mathrm{NaCl} \\
\text { sodium chloride }\end{array}$ & FF-Chemicals & 58.44 & 2.17 & 99.8 & 0.01 \\
\hline $\begin{array}{l}\mathrm{NH}_{4} \mathrm{NO}_{3} \\
\text { ammonium nitrate }\end{array}$ & Sigma & 80.04 & 1.72 & 99.5 & 0.63 \\
\hline $\begin{array}{l}\mathrm{C}_{6} \mathrm{H}_{8} \mathrm{O}_{7} \mathrm{H}_{2} \mathrm{O} \\
\text { citric acid } \cdot \mathrm{H}_{2} \mathrm{O}\end{array}$ & Fisher Chemicals & 210.14 & 1.665 & 99.9 & 0.01 \\
\hline $\begin{array}{l}\mathrm{C}_{4} \mathrm{H}_{6} \mathrm{O}_{6} \\
\mathrm{~L}(+) \text {-tartaric acid }\end{array}$ & Aldrich & 150.09 & 1.76 & 99.5 & 0.01 \\
\hline $\begin{array}{l}\mathrm{C}_{7} \mathrm{H}_{6} \mathrm{O}_{2} \\
\text { benzoic acid }\end{array}$ & Aldrich & 122.12 & 1.27 & 99 & 0.01 \\
\hline $\begin{array}{l}\mathrm{H}_{2} \mathrm{SO}_{4} \\
\text { sulfuric acid }\end{array}$ & Riedel- de Haën & 98.08 & 1.84 & $95-97$ & - \\
\hline
\end{tabular}

$2 \mathrm{kV}$ for the second DMA) were used in the UFO-TDMA. The DMAs were operated with aerosol and sheat flows of 1 and $10 \mathrm{~L} / \mathrm{min}$, respectively. Additionally, to decrease diffusion losses of the ultrafine particles, the length of all lines was minimized in the whole system. Bipolar neutralizer was radioactive ${ }^{63} \mathrm{Ni} \beta$-source (370 MBq, 29.1.2003; AEA Technology QSA GmbH). The ethanol saturator was only used in the sheath line, i.e., particles were treated with ethanol only inside the second DMA by ethanol-rich sheath air (ethanol treatment time was about $1 \mathrm{~s}$ in order to avoid chemical reactions; see Joutsensaari et al., 2004), and ethanol-rich sheath air was produced by bubbling dry air through liquid ethanol, which was heated in a temperature controlled $\left(32^{\circ} \mathrm{C}\right)$ water bath (HBR 4D, IKA). Furthermore, in order to avoid temperature differences in the flows of the second DMA and to keep the temperature constant, the system temperature $\left(\sim 25^{\circ} \mathrm{C}\right)$ was controlled by an effective water bath (RCG CS, Lauda) heating/cooling a water circulation covering the second DMA in the thermal insulated box. Ethanol friendly SolVent (Gelman Sciences) filters were used instead of HEPA (high efficiency particle arresting) filters in the ethanol vapor lines. The saturation ratio of the ethanol vapor was determined using a dew point meter (General Eastern, Hygro M4 with model D-2 chilled mirror sensor; accuracy $\pm 0.2^{\circ} \mathrm{C}$ for water vapor) with a corrosive durable mirror. In order to apply the dew point meter for ethanol vapor (if one excludes water or ethanol, one can measure the other; G. Schultz, private communication, 29 February 2000), dried and purified sheath air (water saturation ratio about 0.03 ) was used. The temperature difference between the saturator and the condenser in the CPC was maximized to $25 \mathrm{~K}$ (condensation particle counter, TSI 3010; Quant et al., 1992) to detect particles down to $6 \mathrm{~nm}$ (Mertes et al., 1995), which is the smallest particle size that can be investigated with this configuration. Correspondingly, the largest measurable particle diameter is about $85 \mathrm{~nm}$. Also $3 \mathrm{~nm}$ size measurements might be possible with the condensation particle counter TSI 3025 when the particles are present in high concentrations in spite of the small inlet flow and high diffusion losses. Because of the comparably low voltages used in the short DMAs, sparks that could ignite the ethanol vapor do not occur. The UFOTDMA system can therefore be used without supervision, making diurnal measurements possible. Typically, the measurement time is between 2-5 min depending on the selected measurement range. Uncertainties of growth factors were estimated for each particle size based on relative growth factor change between consecutive dry size measurements. Saturation ratios normally change less than 0.005 units during the measurements and it has only a very small effect on GF values because organics typically exhibit very smooth growth behavior. Thus, we estimated the error in the GF values to be smaller than 0.01 for $10-50 \mathrm{~nm}$ particles, 0.013 for $8 \mathrm{~nm}$ particles, and 0.017 for $6 \mathrm{~nm}$ particles (for 6 and $8 \mathrm{~nm}$ particles the estimation was carried out based on the 0.1 uncertainty in the particle diameter measurements, i.e. $0.1 / 6$ and $0.1 / 8$ ). 


\subsection{Laboratory measurements}

The aerosol particles were generated from aqueous (particles are usually in aqueous form in atmospheric air) nebulized solutions by a constant output atomizer with a dry and purified airflow (screw compressor, Atlas Copco, ZT30, $25^{\circ} \mathrm{C}$; pre-filter (EU 7); Domnick hunter drier, PNEUDRI MiDAS, DAS 2; HEPA filter) of $3 \mathrm{~L} / \mathrm{min}$. The precursor water (Milli$\mathrm{Q}$ water, Millipore; de-ionized and distilled) solution was fed to the sample line by a syringe pump (Hostec R-50, Finland) and a peristaltic pump (Pharmacia, Fine Chemicals, Sweden). The generated aerosol was diluted immediately after the generator with a dry and purified airflow (screw compressor, Atlas Copco, ZT30, $25^{\circ} \mathrm{C}$; pre-filter (EU 7); Domnick hunter drier, PNEUDRI MiDAS, DAS 2; HEPA filter) of $\sim 27 \mathrm{~L} / \mathrm{min}$. During the dilution (dilution ratio 1/10), the water evaporated from formed droplets, thus forming solid particles. $R H$ (relative humidity) of the aerosol flow was typically about 3\% after the first DMA. Hyppönen (2004) measured the number size distributions of ammonium sulfate particles generated in this way from solutions of various strengths. The mode of the distribution was between 25$30 \mathrm{~nm}$ with the $0.08 \mathrm{M}$ solution and between $50-60 \mathrm{~nm}$ with the $0.8 \mathrm{M}$ solution. It is worth of mentioning that no particles were detected in nucleation mode size class $(6,8$, and $10 \mathrm{~nm})$ when UFO-TDMA measurements were conducted with particles originating from pure water (Milli-Q water, Millipore; de-ionized and distilled).

In order to solve the growth for atmospherically the most relevant inorganic compounds of the lower end of Aitken mode (i.e. $d \leq 50 \mathrm{~nm}$ ) and the nucleation mode (i.e. $\mathrm{d}<20 \mathrm{~nm}$ ) sized particles, growth factors (GFs) were measured for ammonium sulfate, ammonium bisulfate, sodium chloride, iodine tetroxide, iodine pentoxide and ammonium nitrate, respectively, in subsaturated ethanol vapor. Typically, ammonium, sulfate and nitrate ions have been found in air masses from various origins (e.g. Putaud et al., 2004), while iodine oxides (e.g. Burkholder et al., 2004; McFiggans et al., 2004) and sodium chloride (included to sea salt) (O'Dowd et al., 2004) are related to marine origin.

Additionally, GFs were measured for acidic ammoniated sulfate particles created by mixing ammonium bisulfate, a dissociation product of sulfuric acid in the aqueous phase, with mass fraction of $18-50 \%$ of sulfuric acid, which is expected to be an important and typical component in atmospheric air during new particle formation events (e.g. Laaksonen et al., 1995; Kulmala, 2003; Kulmala et al., 2004). Usually, there is a lot of anthropogenic ammonia to neutralize at least a part of sulfuric acid in the tropospheric particles. It is probable in those conditions that sulfuric acid is transformed to more ammonium bisulfate and ammonium sulfate like forms in the aqueous particle phase (Seinfeld and Pandis, 1998). Interestingly, the recent study of Vehkamäki et al. (2004) implies that all sulfuric acid in the atmosphere seems to be bound to tiny ammonium bisulfate clusters which are the basic building blocks in the nucleation process.

For comparison, the growth factors of some atmospherically relevant organic compounds were studied: citric acid $\left(\mathrm{C}_{6} \mathrm{H}_{8} \mathrm{O}_{7}\right)$, tartaric acid $\left(\mathrm{C}_{4} \mathrm{H}_{6} \mathrm{O}_{6}\right)$ and benzoic acid $\left(\mathrm{C}_{7} \mathrm{H}_{6} \mathrm{O}_{2}\right)$. Citric acid has been shown to be an important species in marine waters (Creac'h, 1955) and in sea salt particles (Ming and Russell, 2001). Tartaric acid is found at continental rural and urban particulate matter, mainly during summer, suggesting biogenic origin (Röhrl and Lammel, 2002). Aromatic benzoic acid has been shown to exist in urban particulate matter (e.g. Hamilton et al., 2004) and its source is anthropogenic (e.g. Seinfeld and Pandis, 1998).

Manufacturer, mole weight, density, purity and concentration of the individual compounds in nebulized water solution are summarized in Table 1. Two kinds of nebulized solutions were used for the iodine tetroxide experiments. This is because the stronger solution $(0.05 \mathrm{M})$ did not produce a high enough particle concentration for the nucleation mode sized particles (i.e. 6-20 nm). However, the stronger nebulized solution was needed for the lower end of Aitken mode sized particles (i.e. $20-50 \mathrm{~nm}$ ). Because iodine tetroxide was not commercially available, it was selfmade following guidelines from Daehlie and Kjekshus (1964). The purity of iodine tetroxide was assured by Raman spectroscopy. The density information for it is based on CRC Handbook of Chemistry and Physics (1996). Mass fractions and concentrations in nebulized water solution of sulfuric acid and ammonium bisulfate mixtures are summarized in Table 2.

The working fluid of the UFO-TDMA was ethanol (purity 99.7 mass weight percent). Because the purpose of these experiments is to aid interpreting the results of atmospheric field measurements, the ethanol saturation ratios were chosen to be between $72-88 \%$ which cover typical saturation values used in the field experiments (e.g. Petäjä et al., 2005). In this study, the classified dry diameters were $6,8,10,20,30$ and $50 \mathrm{~nm}$. In order to get dry diameters for GF calculations and to test if measured compounds or mixtures are volatile in the UFO-TDMA system, dry size (no ethanol vapor at all) measurements were carried out for all measured compounds and mixtures at each dry diameter.

\subsection{Theoretical and experimental calculations}

In order to study how the Kelvin effect influences the measured growth factors of particles with different dry diameters $\left(\mathrm{d}_{\mathrm{dry}}\right)$, we first calculated theoretical GFs for the dry particle sizes of 100, 50, 30, 20, 10, 8 and $6 \mathrm{~nm}$ using the Köhler theory (Köhler, 1936) including the Kelvin term and some simplifying assumptions (solution is ideal and dilute; the partial molar volume of solute in solution is equal to the molar volume of pure solute; the surface tension of solution is equal to that of pure ethanol (i.e. $0.02275 \mathrm{~J} / \mathrm{m}^{2}$ ); and the dry particle was assumed to be spherical). The theoretical GFs were solved for ammonium bisulfate, citric acid, tartaric acid 
Table 2. Mass fractions ( $\mathrm{m} \%$ ) and concentrations (mol/L) of the aqueous nebulized solutions for mixtures of sulfuric acid and ammonium bisulfate.

\begin{tabular}{lcccccccc}
\hline Mixtures & $\mathrm{m} \%$ & Conc. $(\mathrm{mol} / \mathrm{L})$ & $\mathrm{m} \%$ & Conc. $(\mathrm{mol} / \mathrm{L})$ & $\mathrm{m} \%$ & Conc. $(\mathrm{mol} / \mathrm{L})$ & $\mathrm{m} \%$ & Conc. $(\mathrm{mol} / \mathrm{L})$ \\
\hline $\mathrm{H}_{2} \mathrm{SO}_{4}+$ & 18 & 0.54 & 25 & 0.63 & 33 & 0.51 & 50 & 1.03 \\
$\mathrm{NH}_{4} \mathrm{HSO}_{4}$ & 82 & 2.07 & 75 & 1.55 & 67 & 0.87 & 50 & 0.87 \\
\hline
\end{tabular}

and benzoic acid particles, respectively, using the following Eqs. (1), (2) and (3):

$\mathrm{GF}=\sqrt[3]{\frac{\frac{\frac{S}{\mathrm{Ke}}}{1-\frac{S}{K e}} \times M_{\text {solvent }} \times \rho_{\text {solute }}}{M_{\text {solute }} \times \rho_{\text {solvent }}}+1}$,

where

$\mathrm{Ke}=\exp \left(\frac{4 \times M_{\text {solvent }} \times \sigma_{\text {solution }}}{R \times T \times \rho_{\text {solvent }} \times d}\right)$,

$\mathrm{GF}=\sqrt[3]{\frac{4 / 3 \times \pi \times\left(\frac{d^{3}}{8}\right)}{V_{\mathrm{dry}}}}$,

where $\mathrm{S}=$ saturation ratio $(0.86), \quad \mathrm{M}_{\text {solvent }}=$ molar mass of solvent $(0.04607 \mathrm{~kg} / \mathrm{mol}), M_{\text {solute }}=$ molar mass of solute $(\mathrm{kg} / \mathrm{mol}), \rho_{\text {solvent }}=$ density of solvent $\left(789.3 \mathrm{~kg} / \mathrm{m}^{3}\right)$, $\rho_{\text {solute }}=$ density of solute $\left(\mathrm{kg} / \mathrm{m}^{3}\right), \mathrm{V}_{\text {dry }}=$ dry volume of particle $\left(\mathrm{m}^{3}\right), \sigma_{\text {solution }}=$ surface tension of solution $\operatorname{droplet}\left(\mathrm{J} / \mathrm{m}^{2}\right)$, $\mathrm{R}=$ molar gas constant $(8.31451 \mathrm{~J} / \mathrm{mol} / \mathrm{K}), \mathrm{T}=$ temperature $(298.15 \mathrm{~K})$ and $\mathrm{d}=$ diameter of solution droplet $(\mathrm{m})$. Densities and molar masses of the solutes were obtained from Table 1. Because the solvent is organic, we expect the assumptions made (especially the assumption that the surface tension equals that of pure ethanol) to hold better for organic compounds than for inorganics.

In practice, we iterated Eqs. (1-3) to obtain the theoretical diameter $\mathrm{d}$ of the grown droplet. After the theoretical GFs $\left(=\mathrm{d} / \mathrm{d}_{\mathrm{dry}}\right)$ had been solved for the different sizes, we calculated the ratios of the theoretical GFs for each pair of consecutive dry particle sizes (i.e. 100/50, 50/30, 30/20, 20/10, $10 / 8$ and 8/6). The theoretical Kelvin terms (Ke) were also solved from Eqs. (1), (2) and (3). Experimental GF ratios for the pairs of dry particle were obtained from the UFO-TDMA measurements, and the experimental Kelvin terms were calculated by substitution of the measured solution droplet diameters (d) into Eq. (2). Finally, the ratios of the theoretical and experimental Kelvin terms ratio were calculated.

\section{Results and discussion}

The results reveal that it is possible to detect the organic fraction in $10 \mathrm{~nm}$ particles by the UFO-TDMA method, even though the sulfuric acid mass fraction would be as high as

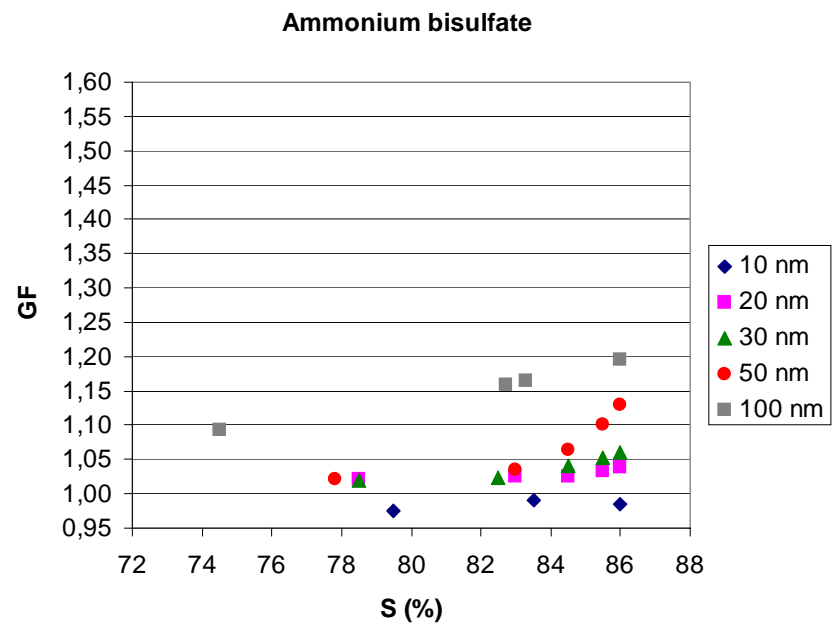

Fig. 2. Experimental growth factors (GFs) of ultrafine (10, 20, 30 and $50 \mathrm{~nm}$, respectively) ammonium bisulfate particles as a function of ethanol saturation ratio (S\%). Error limits are inside the data points in the figure. Also GFs for $100 \mathrm{~nm}$ ammonium bisulfate particles (Joutsensaari et al., 2004) are shown in the figure.

$33 \%$. The solubility and growth information for all measured individual compounds at $86 \%$ saturation ratio have been summarized in Table 3 . The solubility $\left(22^{\circ} \mathrm{C}\right)$ of iodine tetroxide was tested in ethanol by dissolving iodine tetroxide in $1 \mathrm{~L}$ pure ethanol, until the solution was saturated. The result $0.12 \mathrm{~g} / 1 \mathrm{~L}$ means that iodine tetroxide can be regarded as insoluble in ethanol. The solubility for ammonium nitrate was not measured because it was too volatile in $6-50 \mathrm{~nm}$ sizes. The solubility information for other compounds is based on CRC Handbook of Chemistry and Physics (1996).

The laboratory experiments show (Table 3) that atmospherically relevant $50 \mathrm{~nm}$ ammonium sulfate, sodium chloride, iodine pentoxide and iodine tetroxide particles do not grow at $86 \%$ ethanol saturation ratio. This indicates that 1) they will not grow at lower saturation ratios, and 2) smaller particles consisting of these materials will not grow at $86 \%$ or below. Furthermore, ammonium nitrate is too volatile to show any growth.

Figure 2 shows our experimental growth factor data for $10-50 \mathrm{~nm}$ ammonium bisulfate particles at ethanol saturation ratios between $78 \%$ and $86 \%$. It is seen that the GFs of the particles become smaller with decreasing particle size. 
Table 3. Ethanol saturation ratio, water solubility, ethanol solubility and ethanol growth information for particles (10-50 nm) composed of individual compounds. The supercripts ${ }^{1}$ and ${ }^{2}$ refer to CRC Handbook of Chemistry and Physics (1996) and this work, respectively.

\begin{tabular}{|c|c|c|c|c|}
\hline Individual compounds & $\mathrm{S}(\%)$ & sol. $\mathrm{H}_{2} \mathrm{O}^{1}$ & sol. EtOH ${ }^{1}$ & growth $\mathrm{EtOH}^{2}$ \\
\hline $\mathrm{I}_{2} \mathrm{O}_{4}$ & 86 & slightly soluble & insoluble $^{2}$ & no \\
\hline iodine tetroxide & 84 & & & \\
\hline $\mathrm{I}_{2} \mathrm{O}_{5}$, iodine pentoxide & 86 & soluble & insoluble & no \\
\hline $\begin{array}{l}\left(\mathrm{NH}_{4}\right)_{2} \mathrm{SO}_{4} \\
\text { ammonium sulfate }\end{array}$ & 86 & very soluble & insoluble & no \\
\hline $\begin{array}{l}\left(\mathrm{NH}_{4}\right) \mathrm{HSO}_{4}, \\
\text { ammonium bisulfate }\end{array}$ & 86 & very soluble & insoluble & yes/no \\
\hline $\mathrm{NaCl}$, sodium chloride & 86 & soluble & slightly soluble & no \\
\hline $\begin{array}{l}\mathrm{NH}_{4} \mathrm{NO}_{3} \\
\text { ammonium nitrate }\end{array}$ & 84 & very soluble & - & volatile \\
\hline $\mathrm{C}_{6} \mathrm{H}_{8} \mathrm{O}_{7}$, citric acid $\mathrm{H}_{2} \mathrm{O}$ & 86 & very soluble & very soluble & yes \\
\hline $\mathrm{C}_{4} \mathrm{H}_{6} \mathrm{O}_{6}$, tartaric acid & 86 & soluble & soluble & yes \\
\hline $\mathrm{C}_{7} \mathrm{H}_{6} \mathrm{O}_{2}$, benzoic acid & 85 & slightly soluble & very soluble & yes \\
\hline
\end{tabular}

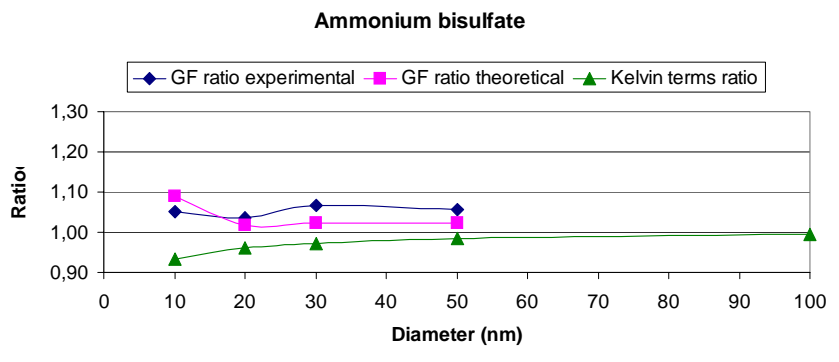

Fig. 3. Experimental and theoretical growth factor (GF) ratio, respectively, for two consecutive ammonium bisulfate dry particle sizes (i.e. 100/50, 50/30, 30/20 and 20/10) at 86\% saturation ratio. Also shown are Kelvin term ratios (theoretical/experimental), for 100, 50, 30, 20 and $10 \mathrm{~nm}$ particles. The denominators determine (e.g. $50 / 30->30 \mathrm{~nm} ; 50 / 50->50 \mathrm{~nm}$ ) the position on the $\mathrm{x}$-axis.

Compared with the behavior of $100 \mathrm{~nm}$ particles measured earlier by Joutsensaari et al. (2004), the GFs of $10-50 \mathrm{~nm}$ particles are markedly lower. It is clear that the Kelvin effect alone is not sufficient to explain the difference between 100 and $50 \mathrm{~nm}$ particles at low saturation ratios. Also at $\mathrm{S} \sim 86 \%$, the experimental GF ratios (see Fig. 3) 100/50 and 50/30, respectively, are a little bit larger than the theoretical ratios. The interpretation of the difference between the theoretical and experimental GF ratios for particles down to $10 \mathrm{~nm}$ is complicated, because experiments show that $10 \mathrm{~nm}$ ammonium bisulfate particles do not grow. However, the ratio of the theoretical and experimental Kelvin terms shows that the experimental Kelvin values are bigger than the theoretical ones for $10-50 \mathrm{~nm}$ particles. Interestingly, at smaller diameters the difference gets bigger, indicating an additional effect beside the Kelvin effect.

In Joutsensaari et al. (2004), we argued that the growth of $100 \mathrm{~nm}$ bisulfate particles is most likely related to their hygroscopicity (i.e. water affinity). The particles were produced from aqueous solution, and even though they were dried at low $R H$, they may have contained some water that prompts the ethanol uptake. When the residence time of the particles in the ethanol vapor was increased from about $2 \mathrm{~s}$ to $30 \mathrm{~s}$ the GF dropped close to unity, which was attributed to sulfate esterification reactions and decreased uptake of ethanol with the associated evaporation of water molecules. Now, it is probable that the amount of water held by the "dry" particles decreases with particle size (as a result of the Kelvin effect experienced by the water molecules). Furthermore, the Laplace pressure of the smaller particles may cause increased chemical reaction constants (e.g. Sanfeld et al., 2000; Sanfeld and Steichen, 2003) and thus, the chemical composition of the smaller particles may change more rapidly. Taken together, the low GFs seen in Fig. 2 may then be explained (1) by decreased water content of the smaller "dry" particles, (2) by the Kelvin effect of the ethanol-bisulfate droplets, and (3) by changed chemical composition due to the Laplace pressure especially in the smallest $(10-20 \mathrm{~nm})$ particles.

The UFO-TDMA measurements show that mixed particles of ammonium bisulfate and sulfuric acid with sulfuric acid mass fractions of $18 \%$ (Fig. 4), 25\% (Fig. 5), 33\% (Fig. 6) and $50 \%$ (Fig. 7) grow, when the particle diameter is $50 \mathrm{~nm}$ and saturation ratio about $85 \%$. The mixtures behave qualitatively in a similar manner as the pure bisulfate particles as the GFs decrease quite pronouncedly as a function of particle size. As with the ammonium bisulfate particles, the decrease is stronger than what would be expected based on the Kelvin effect alone. A point in case is the behavior of the $10 \mathrm{~nm}$ particles which show no growth for the $18-33 \%$ mixtures. Sulfuric acid is even more hygroscopic than ammonium bisulfate, and thus the explanation of the bisulfate particle behavior given above may also apply to the mixed particles. 
$18 \mathrm{~m} \%$ HRSO4

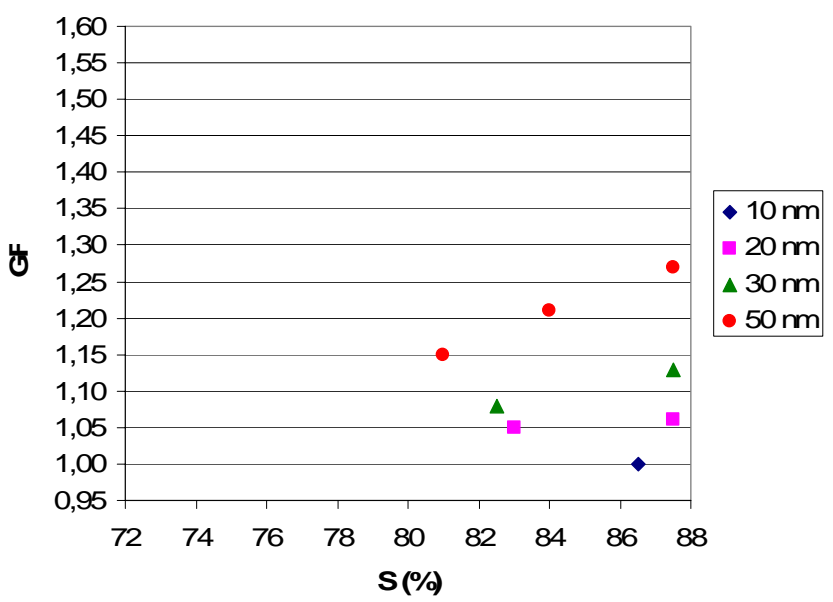

Fig. 4. Experimental growth factors (GFs) of ultrafine particles (10, 20,30 and $50 \mathrm{~nm}$, respectively) with sulfuric acid mass fraction of $18 \%$ as a function of ethanol saturation ratio $(\mathrm{S} \%)$. Error limits are inside the data points in the figure.

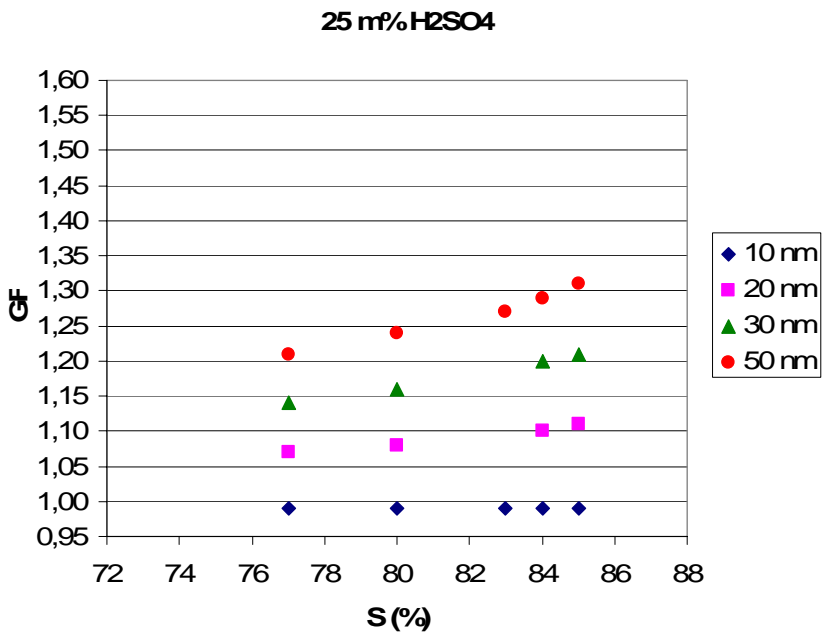

Fig. 5. Experimental growth factors (GFs) of ultrafine particles (10, 20,30 and $50 \mathrm{~nm}$, respectively) with sulfuric acid mass fraction of $25 \%$ as a function of ethanol saturation ratio $(\mathrm{S} \%)$. Error limits are inside the data points in the figure.

The $10 \mathrm{~nm}$ particles consisting of $50 \%$ sulfuric acid solution show modest growth (Fig. 7), however, this should not affect our conclusions concerning atmospheric particles since the sulfuric acid solutions found in the boundary layer will always be much more dilute. For example, a low ammonia concentration environment study of Boy et al. (2005) estimated that the sulfuric acid fraction is between 3 to $17 \%$ in newly formed particles during nucleation events. The very recent study of Fiedler et al. (2005) concluded that the percentage contribution of sulfuric acid to new particle formation and growth at a continental boreal forest area and at a

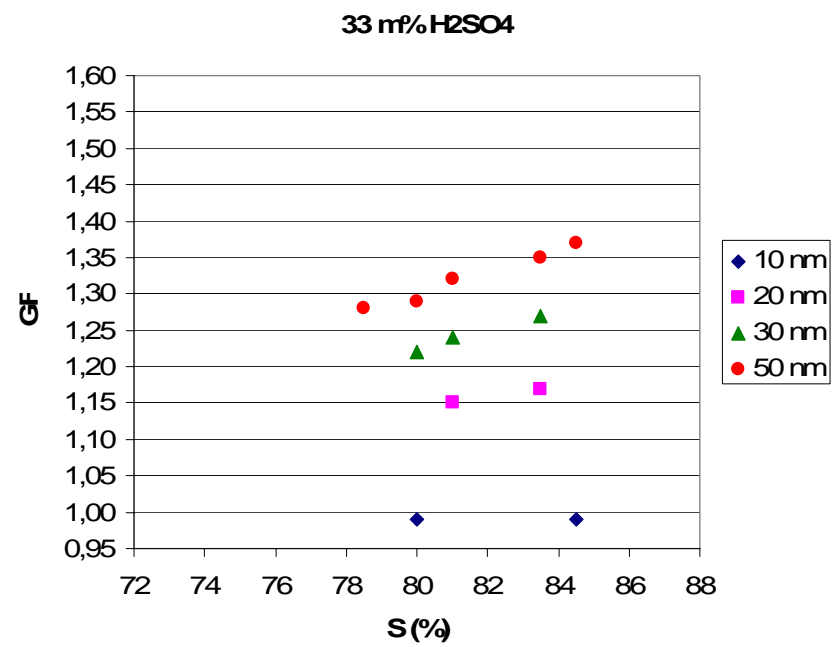

Fig. 6. Experimental growth factors (GFs) of ultrafine particles (10, 20,30 and $50 \mathrm{~nm}$, respectively) with sulfuric acid mass fraction of $33 \%$ as a function of ethanol saturation ratio $(\mathrm{S} \%)$. Error limits are inside the data points in the figure.

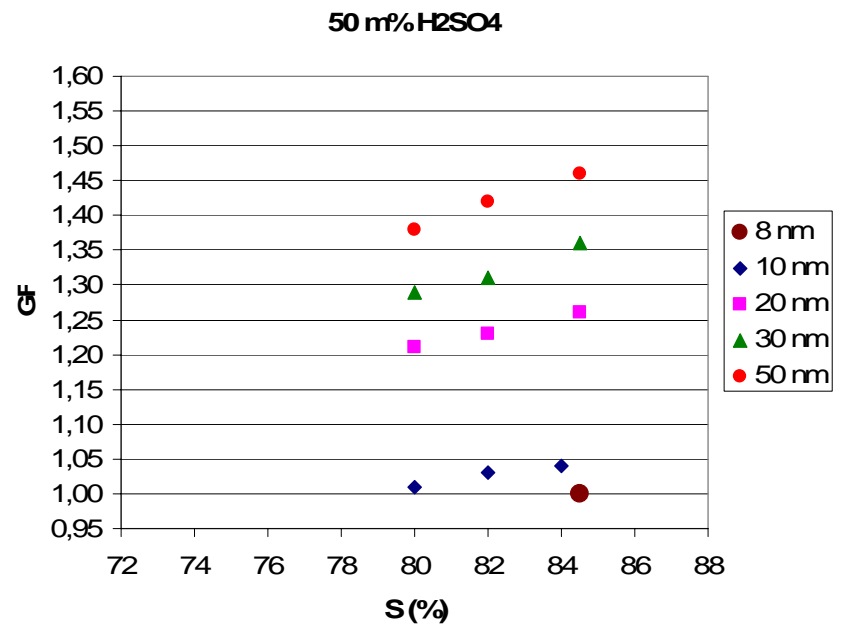

Fig. 7. Experimental growth factors (GFs) of ultrafine (8, 10, 20, 30 and $50 \mathrm{~nm}$, respectively) particles with sulfuric acid mass fraction of $50 \%$ as a function of ethanol saturation ratio $(\mathrm{S} \%)$. Error limits are inside the data points in the figure.

polluted continental region are below $10 \%$ at both places. Thus, sulfuric acid mass fraction of $18-33 \%$ used in our laboratory UFO-TDMA measurements is high enough to indicate that it is possible to carry out the UFO-TDMA field measurements at such a saturation ratio that sulfuric acid will not cause any growth for $10 \mathrm{~nm}$ particles.

In contrast to inorganic compound growth behavior, the organic compounds citric acid (Fig. 8), tartaric acid (Fig. 9) and benzoic acid (Fig. 10) exhibit clear growth behavior, when particle size is $10-50 \mathrm{~nm}$ or even below that. Again, GFs decrease with decreasing particle size. The size dependence of 


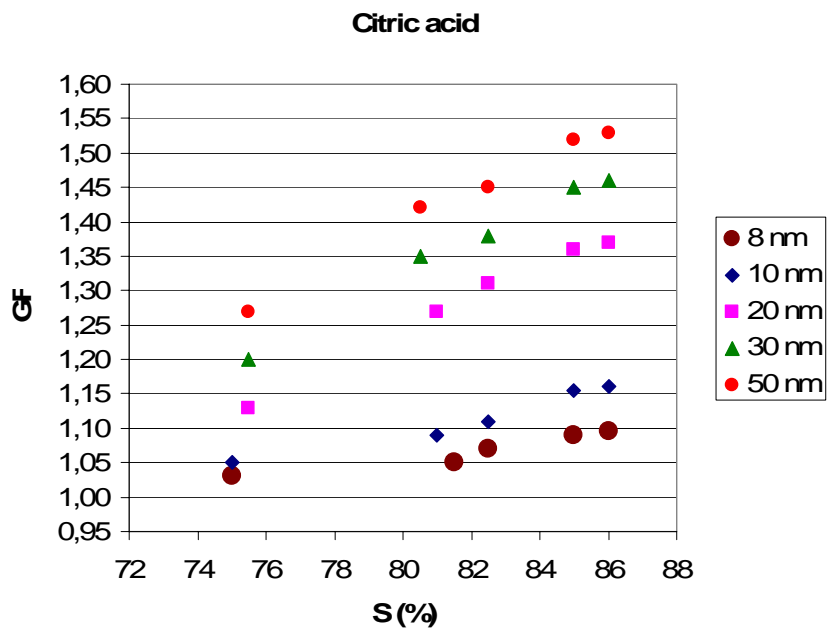

Fig. 8. Experimental growth factors (GFs) of ultrafine $(8,10,20,30$ and $50 \mathrm{~nm}$, respectively) citric acid particles as a function of ethanol saturation ratio $(\mathrm{S} \%)$. Error limits are inside the data points in the figure.

Tartaric acid

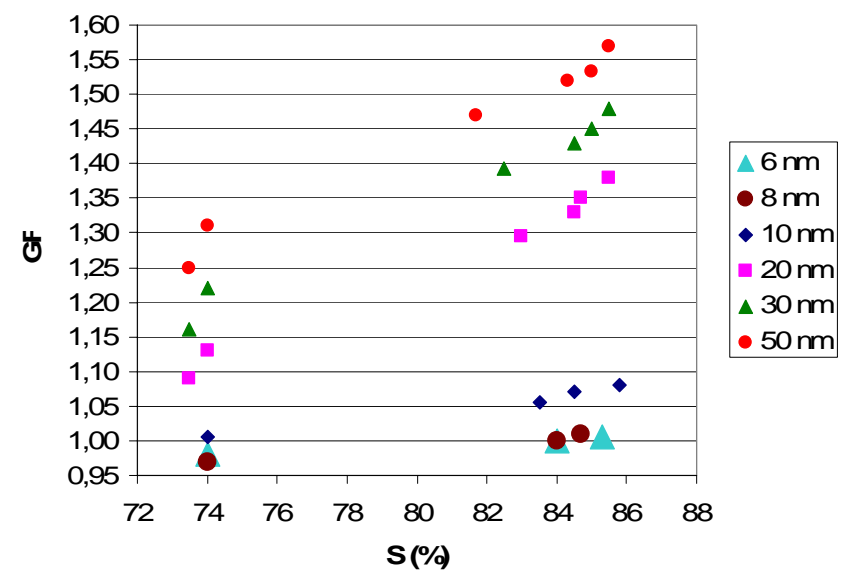

Fig. 9. Experimental growth factors (GFs) of ultrafine (6, 8, 10, 20, 30 and $50 \mathrm{~nm}$, respectively) tartaric acid particles as a function of ethanol saturation ratio (S\%). Error limits are inside the data points in the figure.

the GFs may be explained for the most part with the Kelvin effect down to $20 \mathrm{~nm}$ particles. However, between 20 and $10 \mathrm{~nm}$, quite a sizeable gap appears. Figures 11-13 show that theoretical GF ratios are smaller than the experimental ones, especially between 20 and $10 \mathrm{~nm}$. Once again, the theoretically calculated Kelvin effect alone is not sufficient to explain the differences for $10-20 \mathrm{~nm}$ particles, although also the theoretical Kelvin effect increases strongly between those sizes. The curves showing ratios of theoretical and experimental Kelvin terms (Figs. 11-13) also illustrate that ratios are near 1 for bigger sizes, but show increasing departure from unity as the particle sizes decrease. Thus, the additional

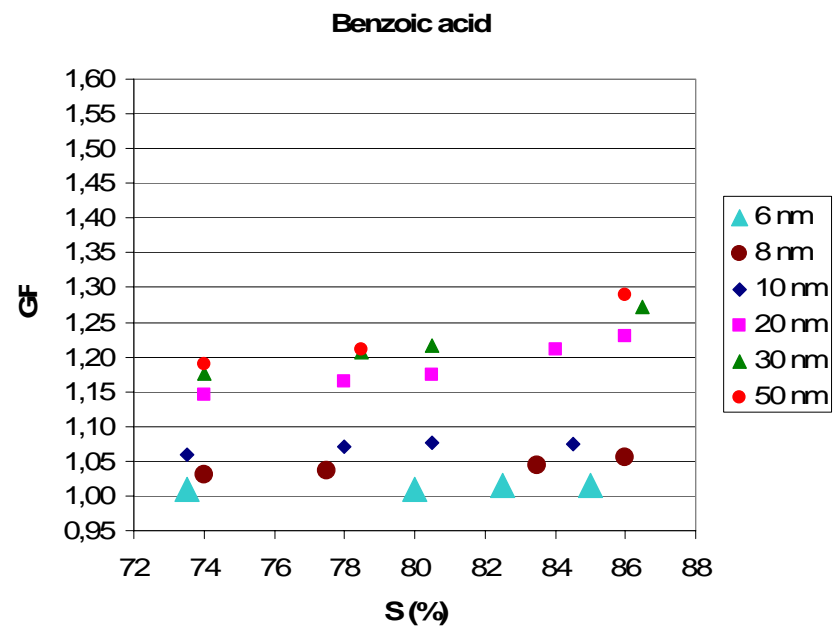

Fig. 10. Experimental growth factors (GFs) of ultrafine (6, 8, 10, 20,30 and $50 \mathrm{~nm}$, respectively) benzoic acid particles as a function of ethanol saturation ratio $(\mathrm{S} \%)$. Error limits are inside the data points in the figure.

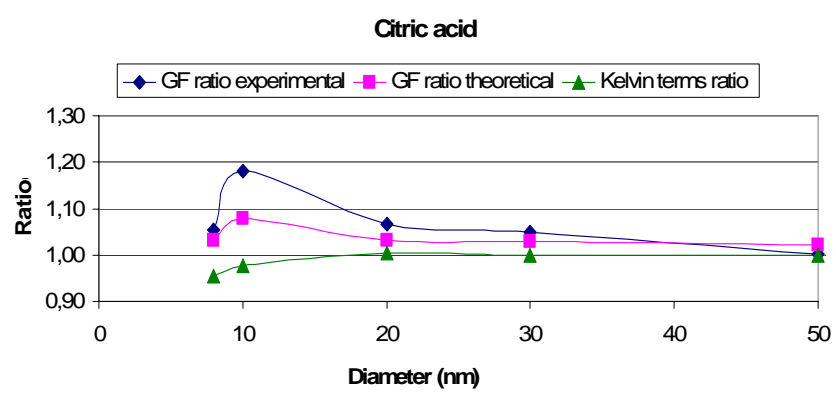

Fig. 11. Experimental and theoretical growth factor (GF) ratio, respectively, for two consecutive citric acid dry particle sizes (i.e. 100/50, 50/30, 30/20, 20/10 and 10/8) at 86\% saturation ratio. Also shown are Kelvin term ratios (theoretical/experimental), for 50, 30, 20, 10 and $8 \mathrm{~nm}$ particles. The denominators determine (e.g. $50 / 30->30 \mathrm{~nm} ; 50 / 50->50 \mathrm{~nm}$ ) the position on the $\mathrm{x}$-axis.

reason for that kind of behavior could once more be that the chemical composition of the smallest particles changes more rapidly (i.e. within the time the particles spend inside the UFO-TDMA) due to their higher Laplace pressure. The correctness of this explanation can be checked by varying the residence times of different sized particles in ethanol vapor and measuring the GFs. However, because of experimental difficulties related to increased diffusion losses of the smallest particles when the residence time is increased, we will leave reporting of the results to a follow-up publication.

An interesting question is whether the present method for the detection of the organic fraction can be extended to dry particles larger than $10 \mathrm{~nm}$. It should be noted that ammonium bisulfate does not really grow any more at ethanol saturation ratios of 0.82 and below. Thus, if solar radiation is not efficient enough to produce lot of sulfuric acid 


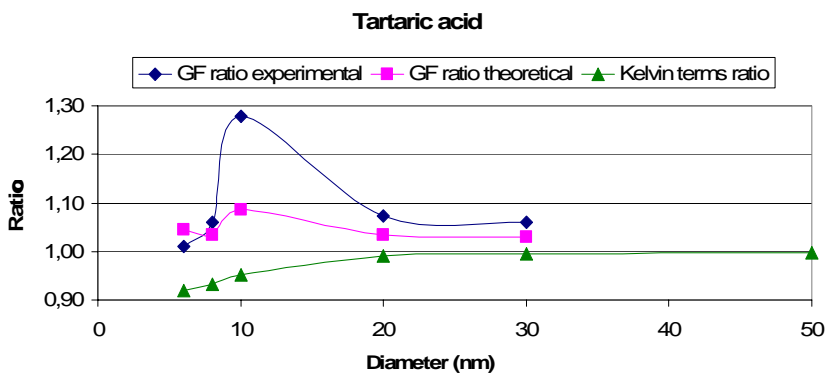

Fig. 12. Experimental and theoretical growth factor (GF) ratio, respectively, for two consecutive tartaric acid dry particle sizes (i.e. $50 / 30,30 / 20,20 / 10,10 / 8$ and $8 / 6$ ) at $86 \%$ saturation ratio (experimental GF values for 8 and $6 \mathrm{~nm}$ are at $\mathrm{S} \sim 85 \%$ ). Also shown are Kelvin term ratios (theoretical/experimental), for 50, 30, 20, 10,8 and $6 \mathrm{~nm}$ particles. The denominators determine (e.g. 50/30 $>30 \mathrm{~nm} ; 50 / 50->50 \mathrm{~nm}$ ) the position on the $\mathrm{x}$-axis.

(e.g. cloudy sky or night time), or sulfuric acid is aged in the particle phase (i.e. reacted to less acidic form), or ammonia concentration is high enough for immediate neutralization (e.g. polluted regions), the $20-50 \mathrm{~nm}$ sulfate particles are not expected to grow at ethanol saturation ratios below 0.82 . It remains an open question whether it is possible to find such an ethanol saturation ratio at which highly concentrated (e.g. $18 \mathrm{~m} \%$ ) sulfuric acid particles do not grow but many types of organic particles do. As an interesting detail, it has been shown that sulfuric acid concentrations are generally relatively low (i.e. percentage contribution below 10\%) in usual lower troposphere situations (e.g. diesel engine at $40 \%$ engine load, Tobias et al., 2001; a boreal forest site and a polluted continental area, Fiedler et al., 2005).

\section{Conclusions}

In this study, we have applied the UFO-TDMA method to detect the presence of organic fraction in atmospherically relevant nucleation mode sized particles. Based on our laboratory measurements, the usefulness of the UFO-TDMA in the field experiments will arise especially from the fact that the most relevant and common inorganic compounds (i.e. ammonium sulfate, ammonium bisulfate, sodium chloride, iodine tetroxide and iodine pentoxide) do not show growth in the UFO-TDMA when the particle size is $10 \mathrm{~nm}$ and ethanol saturation ratio is below $86 \%$. Furthermore, mixed $10 \mathrm{~nm}$ particles of ammonium bisulfate and sulfuric acid $\mathrm{H}_{2} \mathrm{SO}_{4}$ mass fractions below $33 \%$ do not grow at $85 \%$ saturation ratio while atmospherically relevant organic compounds, citric acid, tartaric acid, and benzoic acid do exhibit measurable growth at those conditions.

Naturally, real atmospheric nucleation mode particles can be composed of mixtures of inorganic and organic compounds. It is also possible that the inorganic fraction hinders the growth of the organic fraction in the UFO-TDMA.

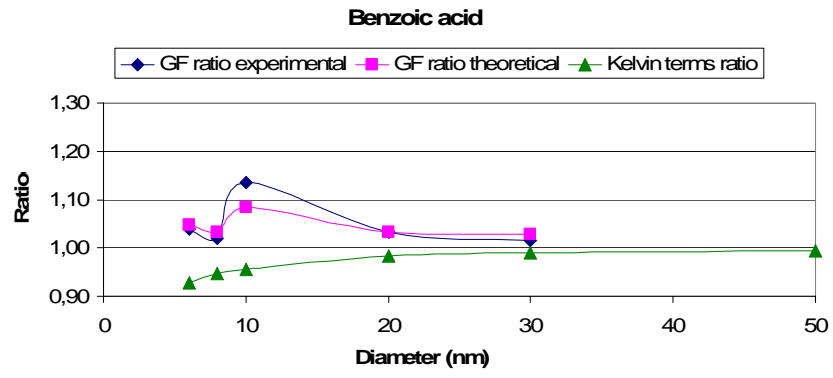

Fig. 13. Experimental and theoretical growth factor (GF) ratio, respectively, for two consecutive benzoic acid dry particle sizes (i.e. $50 / 30,30 / 20,20 / 10,10 / 8$ and $8 / 6$ ) at $86 \%$ saturation ratio (experimental GF values for 10 and $6 \mathrm{~nm}$ particles are at $\mathrm{S} \sim 85$ ). Also shown are Kelvin term ratios (theoretical/experimental), for 50, 30, 20, 10, 8 and $6 \mathrm{~nm}$ particles. The denominators determine (e.g. $50 / 30->30 \mathrm{~nm} ; 50 / 50->50 \mathrm{~nm}$ ) the position on the $\mathrm{x}$-axis.

Furthermore, all organic compounds do not grow in subsaturated ethanol vapor. Therefore, when the UFO-TDMA does not show any growth for ambient $10 \mathrm{~nm}$ or below that particles, it is not certain that the particles would be purely inorganic. However, in cases where $10 \mathrm{~nm}$ or below that ambient particle growth is detected, it can be quite safely concluded that the particles do contain organic matter. The results of Petäjä et al. (2005), for example, showed clear growth for $10 \mathrm{~nm}$ particles at ethanol saturation ratio of about $82 \%$. That also proves the usefulness of the UFO-TDMA in studying the composition of nucleation mode sized particles in the field experiments. Thus, we believe that the UFO-TDMA will be an important method to shed light on the nucleation mode particle compositions in different atmospheric conditions.

In the future, laboratory experiments with different organic compounds will be carried out in order to evaluate effects of different functional groups and chain length to the growth behavior of organic compounds in nucleation mode sized particles. Furthermore, mixtures of atmospherically relevant organic compounds and inorganic compounds, which are specific to certain field environments, will be carried out in order to describe nucleation mode sized particles also more quantitatively, in addition to the current qualitative analysis.

Acknowledgements. This work was supported by EU (European Union) 5th Framework Programme through the QUEST (Quantification of Aerosol Nucleation in the European Boundary Layer) project, Emil Aaltonen Foundation, and Academy of Finland through the Center of Excellence programme.

Edited by: R. Hitzenberger

\section{References}

Boy, M., Kulmala, M., Ruuskanen, T. M., Pihlatie, M., Reissell, A., Aalto, P. P., Keronen, P., Dal Maso, M., Hellen, H., Hakola, 
H., Jansson, R., Hanke, M., and Arnold, F.: Sulphuric acid closure and contribution to nucleation mode particle growth, Atmos. Chem. Phys., 5, 863-878, 2005,

SRef-ID: 1680-7324/acp/2005-5-863.

Burkholder, J. B., Curtius, J., Ravisshankara, A. R., and Lovejoy, E. R.: Laboratory studies of the homogeneous nucleation of iodine oxides, Atmos. Chem. Phys., 4, 19-34, 2004,

SRef-ID: 1680-7324/acp/2004-4-19.

CRC Handbook of Chemistry and Physics, 77th edition, CRC press, Inc., 1996.

Creac'h, P. V.: Presence of citric and malic acids in littoral marine waters, Hebd. Seances Acad. Sci., 240, 2551-2553, 1955.

Daehlie, G. and Kjekshus, A.: Iodine oxides, Part I., Acta Chem. Scand., 18, 144-156, 1964.

Fiedler, V., Dal Maso, M., Boy, M., Aufmhoff, H., Hoffmann, J., Schuck, T., Birmili, W., Hanke, M., Uecker, J., Arnold, F., and Kulmala, M.: The contribution of sulphuric acid to atmospheric particle formation and growth: a comparison between boundary layers in Northern and Central Europe, Atmos. Chem. Phys., 5, 1773-1785, 2005,

\section{SRef-ID: 1680-7324/acp/2005-5-1773.}

Hämeri, K., Väkevä, M., Hansson, H.-C., and Laaksonen, A.: Hygroscopic growth of ultrafine ammonium sulphate aerosol measured using an ultrafine tandem differential mobility analyzer, J. Geophys. Res., 105(D17), doi:10.1029/2000JD900220, 22 232$22242,2000$.

Hamilton, J. F., Webb, P. J., Webb, A. C., Lewis, A. C., Hopkins, J. R., Smith, S., and Davy, P.: Partially oxidized organic components in urban aerosol using GCXGX-TOF/MS, Atmos. Chem. Phys., 4, 1279-1290, 2004,

\section{SRef-ID: 1680-7324/acp/2004-4-1279.}

Hyppönen, N.: Deliquesence of nanometer-sized ammonium sulfate particles in humidified air (in Finnish), Master's thesis, University of Kuopio, Department of Applied Physics, 2004.

Ibald-Mulli, A., Wichmann, H. E., Kreyling, W., and Peters, A.: Epidemiological evidence on health effects of ultrafine particles, J. Aerosol Med., 15(2), 189-201, 2002.

Joutsensaari, J., Vaattovaara, P., Vesterinen, M., Hämeri, K., and Laaksonen, A.: A novel tandem differential mobility analyzer with organic vapor treatment of aerosol particles, Atmos. Chem. Phys., 1, 51-60, 2001,

SRef-ID: 1680-7324/acp/2001-1-51.

Joutsensaari, J., Toivonen, T., Vaattovaara, P., Vesterinen, M., Vepsäläinen, J., and Laaksonen, A.: Time-resolved growth behavior of acid aerosols in ethanol vapor with a tandem-DMA technique, J. Aerosol Sci., 35, 851-867, 2004.

Knutson, E. O. and Whitby, K. T.: Aerosol classification by electric mobility: apparatus, theory and applications, J. Aerosol Sci., 6, 443-451, 1975.

Köhler, H.: The nucleus in and the growth of hygroscopic droplets, Trans. Faraday Soc., 32, 1152-1161, 1936.

Kulmala, M.: How particles nucleate and grow, Science, 307(5647), 1000-1001, 2003.

Kulmala, M., Vehkamäki, H., Petäjä, T., Dal Maso, M., Lauri, A., Kerminen, V.-M., Birmili, W., and McMurry, P. H.: Formation and growth rates of ultrafine atmospheric particles: A review of observations, J. Aerosol Sci., 35(2), 143-176, 2004.

Laaksonen, A., Talanquer, V., and Oxtoby, D. W.: Nucleationmeasurements, theory, and atmospheric applications, Ann. Rev.
Phys. Chem., 46, 489-524, 1995.

Mäkelä, J., Aalto, P., Jokinen, V., Pohja, T., Nissinen, A., Palmroth, S., Markkanen, T., Seitsonen, K., Lihavainen, H., and Kulmala, M.: Observations of ultrafine aerosol particle formation and growth in boreal forest, Geophys. Res. Lett., 24, 1219-1222, 1997.

Mäkelä, J. M., Hoffmann, T., Holzke, C., Väkevä, M., Suni, T., Aalto, P., Tapper, U., Kauppinen E., and O'Dowd C. D.: Biogenic iodine emissions and identification of end-products in coastal ultrafine particles during nucleation burst, J. Geophys. Res., 107(D19), 8110, PAR 1-14, 2002.

McFiggans, G., Coe, H., Burgess, R., Allan, J., Cubison, M., Alfarra, R., Saunders, R., Saiz-Lopez, A., Plane, J. M. C., Wevill, D., Carpenter, L., Richard, A. R., and Monks, P. S.: Direct evidence for coastal iodine particles from Laminaria macroalgae linkage to emissions of molecular iodine, Atmos. Chem. Phys., 4, 701-713, 2004,

SRef-ID: 1680-7324/acp/2004-4-701.

Mertes, S., Schröder, F., and Wiedensohler, A.: The particle detection efficiency curve of the TSI-3010 CPC as a function of temperature difference between saturator and condenser, Aerosol Sci. Technol., 23, 257-261, 1995.

Ming, Y. and Russell, L.: Predicted hygroscopic growth of sea salt aerosol, J. Geophys. Res., 106, 28 259-28 274, 2001.

O'Dowd, C. D., Aalto, P. P., Yoon, Y. J., and Hämeri, K.: The use of the pulse height analyzer ultrafine condensation particle counter (PHA-UCPC) technique applied to sizing of nucleation mode particles of differing chemical composition, J. Aerosol Sci., 35, 205-216, 2003.

O’Dowd, C. D., Facchini, M. C., Cavalli, F., Ceburnis, D., Mircea, M., Dececari, S., Fuzzi, S., Yoon, Y. J., and Putaud, J.-P.: Biogenically driven organic contribution to marine aerosol, Nature, 431, 676-680, 2004.

Petäjä, T., Kerminen, V.-M., Hämeri, K., Vaattovaara, P., Joutsensaari, J., Junkermann, W., Laaksonen, A., and Kulmala, M.: Effects of $\mathrm{SO}_{2}$ oxidation on ambient aerosol growth in water and ethanol vapours, Atmos. Chem. Phys, 5, 767-779, 2005,

SRef-ID: 1680-7324/acp/2005-5-767.

Putaud, J.-P., Van Dingenen, R., Dell'Acqua, A., Raes, F., Matta, E., Descesari, S., Facchini, M. C., and Fuzzi, S.: Size-segregated aerosol mass closure and chemical composition in Monte Cimone (I) during MINATROC, Atmos. Chem. Phys., 4, 889-902, 2004,

SRef-ID: 1680-7324/acp/2004-4-889.

Quant, F. R., Caldow, R., Sem, G. J., and Addison, T. J.: Performance of condensation particle counters with three continuous flow design, J. Aerosol. Sci., 23, 405-408, 1992.

Reischl, G. P.: Measurement of ambient aerosols by the different mobility analyzer method: concepts and realization criteria for the size range between 2 and $500 \mathrm{~nm}$, Aerosol Sci. Technol., 14, 5-24, 1991.

Röhrl, A. and Lammel, G.: Determination of malic and other $\mathrm{C}_{4}$ dicarboxylic acids in atmospheric aerosol samples, Chemosphere, 46, 1195-1199, 2002.

Sanfeld, A., Sefiane, K., Benielli, D., and Steinchen, A.: Does capillarity influence chemical reaction in drops and bubbles? A thermodynamic approach, Adv. Colloid Interface Sci., 86, 153-193, 2000.

Sanfeld, A. and Steinchen, A.: Does the size of small objects influ- 
ence chemical reactivity in living systems, C. R. Biologies, 326, 141-147, 2003.

Seinfeld, J. and Pandis, S.: Atmospheric chemistry and physics: from air pollution to climate change, John Wiley \& Sons, Inc., New York, 1998.

Slingo, A.: Sensitivity of the Earth's radiation budget to changes in low clouds, Nature, 343, 49-51, 1990.

Smith, J., Moore, K., McMurry, P., and Eisele, F.: Atmospheric measurements of sub-20 nm diameter particle chemical composition by Thermal Desorption Chemical Ionization Mass Spectrometry, Aerosol. Sci. Technol., 38, 100-111, 2004.
Tobias, H. J., Bewing, D. E., Ziemann, P. J, Sakurai, H., Zuk, M., McMurry, P. H., Zarling, D., Waytulonis, R., and Kittelson, D. B.: Chemical analysis of diesel engine nanoparticles using a Nano-DMA/Thermal desorption particle beam mass spectrometer, Env. Sci. Technol., 35, 2233-2243, 2001.

Vehkamäki, H., Napari, I., Kulmala, M., and Noppel, M.: Stable ammonium bisulphate clusters in the atmosphere, Phys. Rev. Lett., 93, 148 501-148 504, 2004.

Winklmayr, W., Reischl, G. P., Lindner, A. O., and Berner, A.: A new electromobility spectrometer for the measurement of aerosol size distributions in the size range from 1 to $1000 \mathrm{~nm}$, J. Aerosol Sci., 22, 289-296, 1991. 